\title{
Risk Factors for Complications after Skin-Sparing and Nipple-Sparing Mastectomy
}

\author{
Felix J. Paprottka ${ }^{a}$ Christopher L. Schlett ${ }^{b}$ Rosalia Luketina ${ }^{c}$ \\ Karolin Paprottka ${ }^{d}$ Dalius Klimas ${ }^{e}$ Christine Radtke ${ }^{f}$ Detlev Hebebrand ${ }^{a}$ \\ aDepartment of Plastic, Aesthetic, Reconstructive and Hand Surgery, AGAPLESION Diakonieklinikum Rotenburg,

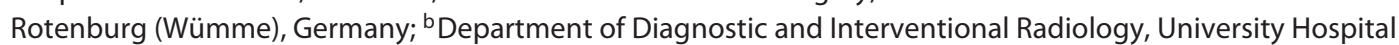 \\ Heidelberg, Heidelberg, Germany; ${ }^{\mathrm{C} D e p a r t m e n t}$ of Plastic, Aesthetic, Hand and Reconstructive Surgery, Hannover \\ Medical School, Hannover, Germany; ${ }^{\text {d}}$ Department of Clinical Radiology, Campus Grosshadern, Ludwig-

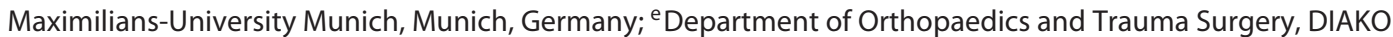

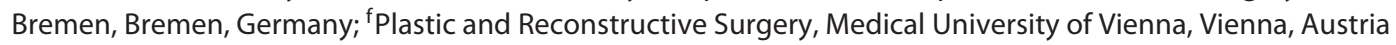

\section{Keywords}

Breast cancer · Breast reconstruction · Nipple-sparing mastectomy $\cdot$ Skin-sparing mastectomy $\cdot$ Risk factors

\section{Abstract}

Introduction: In order to achieve a complication-free breast reconstruction, it is fundamental for each individual patient case to determine preoperatively certain risk factors that might have a negative impact on the postoperative result after skin-sparing (SSM) or nipple-sparing mastectomy (NSM). Methods: A retrospective study of 39 female breast cancer patients who received SSM or NSM breast reconstruction in our department (time interval: 2010-2015), was performed. The study focus is on determining patient characteristics (e.g., demographics, history of radiotherapy/chemotherapy, menopausal status, amount of resected breast tissue) leading to higher complication rates. Results: Overall, 50 mastectomies (27 SSM and 23 NSM) with 6 immediate and 35 immediate 2-stage tissue expander breast reconstructions amounting to a total of 41 surgical interventions $(n=41)$ were carried out. Median follow-up time was 2 years and 5 months (range 121-1,863 days). Increased complication rates were associated with the following patient characteristics: age $>50$ years $(p<0.05)$ and personal history of cardiovascular disease $(p<$ $0.05)$. Increased but not significant risk factors included postmenopausal status ( $p=0.07$ ), radiotherapy prior to SSM/NSM $(p=0.06)$, and weight of resected breast tissue $>438 \mathrm{~g}(p=$
0.09). Conclusion: This work identified age $>50$ years and personal history of cardiovascular disease to be risk factors for increased complication rates following SSM and NSM. Therefore, the given findings should be taken into account when selecting patients for these 2 procedures.

C 2019 S. Karger AG, Basel

\section{Introduction}

The diagnosis of breast cancer - with a lifetime incidence of 1 out of 8 women - brings about many major challenges for the patient and the treating breast surgeon [1]. In 1991, skin-sparing mastectomy (SSM) was first described by Toth and Lappert [2] with resecting the whole breast and nipple-areola complex while preserving the skin envelope including the native inframammary fold [1]. The first report of nipple-sparing mastectomy (NSM) came from Hinton et al. [3], who stated that NSM achieved comparable local recurrence rates and survival rates compared to radical mastectomy [1]. Patient selection for NSM should be based on study of breast duct anatomy by magnetic resonance imaging, mammographic tumornipple distance, and obligatory intraoperative frozen section from retroareolar tissue [4]. Moreover, tumor size, axillary lymph node status, lymphovascular invasion, and degree of intraductal component are factors used to include SSM/NSM candidates [4].

\section{KARGER}

(C) 2019 S. Karger AG, Basel 
Table 1. Patient characteristics in our study cohort

\begin{tabular}{ll}
\hline Patient characteristics & Study outcome \\
\hline Patient age & $\emptyset 49$ years (range 35-74 years) \\
Menopausal status & $\emptyset$ BMI 24.5 (healthy weight) \\
Time interval (first diagnosis to SSM/NSM) & 46 days \\
Operation time (SSM/NSM) & $\emptyset 2 \mathrm{~h} 18 \mathrm{~min}$ \\
Implant volume (SSM/NSM) & $\emptyset 346 \mathrm{~mL}$ (range 130-650 mL) \\
Time until drainage removal & $\emptyset 6$ days \\
Revision needed to achieve R0 resection & In 26\% of all patients \\
\hline
\end{tabular}

Information about patient age, menopausal status, time interval (event of breast cancer diagnosis until performing of SSM/NSM), operation time needed for SSM/NSM, implant volume used for SSM/NSM, time until drainage removal in days, revision needed to achieve R0 resection in all patients (in \%) in our patient cohort $(n=39)$ is presented.

In this context, SSM and NSM offer essential treatment options to achieve a safe oncologic and aesthetically pleasing breast reconstruction (BR). Both techniques have each been established in the literature to be an effective alternative to radical mastectomy $[5,6]$. The aim of this study is to determine patient characteristics such as patient age, smoking, alcohol abuse, patient weight (BMI), general health factors, history of radiotherapy and/or chemotherapy prior to surgery, menopausal status, and amount of resected breast tissue leading to higher complication rates.

\section{Patients and Methods}

A retrospective data analysis was performed including all patients who underwent SSM/NSM followed by immediate or immediate 2 -stage tissue expander BR by experienced plastic surgery specialists within our department (time interval: 2010-2015). After a detailed pre-operation discussion, the informed patient decided which kind of BR approach should be performed. In all cases with only minimal breast tissue thickness, a final BR with free tissue transfer was strongly recommended. If no immediate BR after SSM/NSM was done, immediate 2-stage tissue expander BR with implementation of a "Becker" expander by Mentor (Santa Barbara, CA, USA) was performed in order to expand the skin envelope and/or avoid skin shrinkage. The initial fill volume for the expanders was set to be around $100 \mathrm{~mL}$ less than the preoperative estimated breast volume in order to avoid postoperative cutaneous shrinkage. Then every 2-4 weeks thereafter, another $40-80 \mathrm{~mL}$ of fill volume were added to the expander until the desired breast size was reached. In the rare case of a skin breakdown (while receiving the expander treatment), expander explantation had to be performed. In all cases of implant-based BR, silicone "Style 410 implants" by Allergan (Parsippany-Troy Hills, NJ, USA) were used for subpectoral augmentation. Surgical drains were placed in all operations (one per side). A single dose of intravenous antibiotics was administered intraoperatively. If free tissue transfer was performed, the first choice of treatment was deep inferior epigastric perforator flap. If certain contraindications for using deep inferior epigastric perforator flap were given, inferior gluteal artery perforator flap was chosen as a second reconstructive option.

Being part of our hospital's Breast Center, our Plastic Surgery Department was integrated into an interdisciplinary treatment of breast cancer patients together with the Department of Gynaecology, Oncology, Pathology, Radiology, and Radiotherapy. Patients who were planned by our Breast Center for adjuvant radio- or chemotherapy following SSM/NSM were excluded from this study.

Prior to NSM/SSM surgery, the Department of Gynaecology was responsible for staging each patient. Patients selected for NSM must have had peripherally located tumors $<3 \mathrm{~cm}$ in size and clinically negative lymph nodes on levels I-III in the axillae. Specific pathologic assessment of the nipple margin was performed, and nipple removal was indicated if involvement with cancer was seen. For SSM, histopathological proof with no signs of cutaneous tumor cell infiltration is needed in order to perform this surgical procedure and maintain the skin envelope.

Patient cases with simultaneous oncologic and prophylactic SSM/NSM (bilateral) were counted as one surgical event. For statistical reasons, it was more precise to use the total amount of surgical interventions because as a statistical end factor, occurrence of postoperative complications was set. Therefore, in our patient data set, the number of surgical events $(n=41)$ compared to all performed SSM/NSM $(n=50)$ procedures is lower.

\section{Follow-Up}

A single investigator (F.J.P.) independently conducted patient follow-up by reviewing medical charts and routine postoperative exams at standardized time increments.

\section{Outcome Measures}

The primary end point was the occurrence of short-term complications ( $\leq 6$ months) defined as skin necrosis (breakdown of the skin envelope without implant exposure), infection (postoperative superficial or profound infection of the breast), seroma (postoperative clear serous fluid formation), hematoma (due to [sub-]active bleeding), or implant exposure (breakdown of the skin envelope with implant exposure). Secondary study end points were long-term complications ( $>6$ months) including implant loss (incident that resulted in implant explantation) and malposition of the implant (implant dislocation resulting in reoperation).

Statistical analysis was performed in order to determine if potential risk factors such as patient age, smoking, alcohol and/or drug abuse, high or low patient weight (BMI), general health fac- 
41 OPs with 50 SSM/NSM

in 39 pat. (TI: 2010 - 2015)
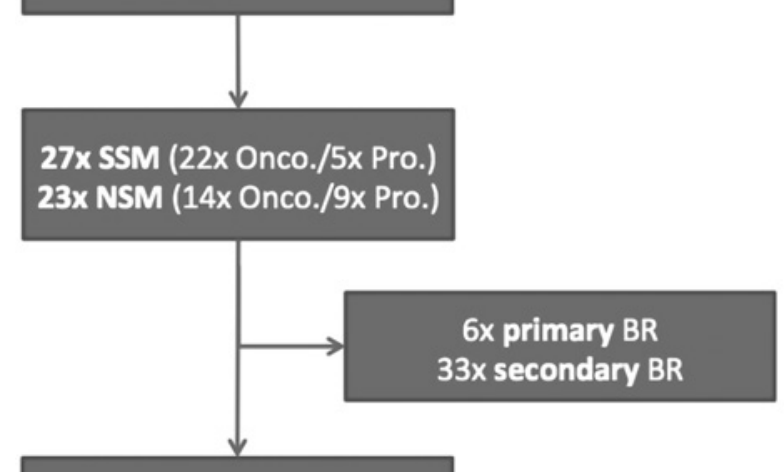

BR after $\varnothing 131 d(0-665 d)$

with $37 x$ implants, $13 x$ free

flaps $(12 x$ DIEP $+1 x i-G A P)$

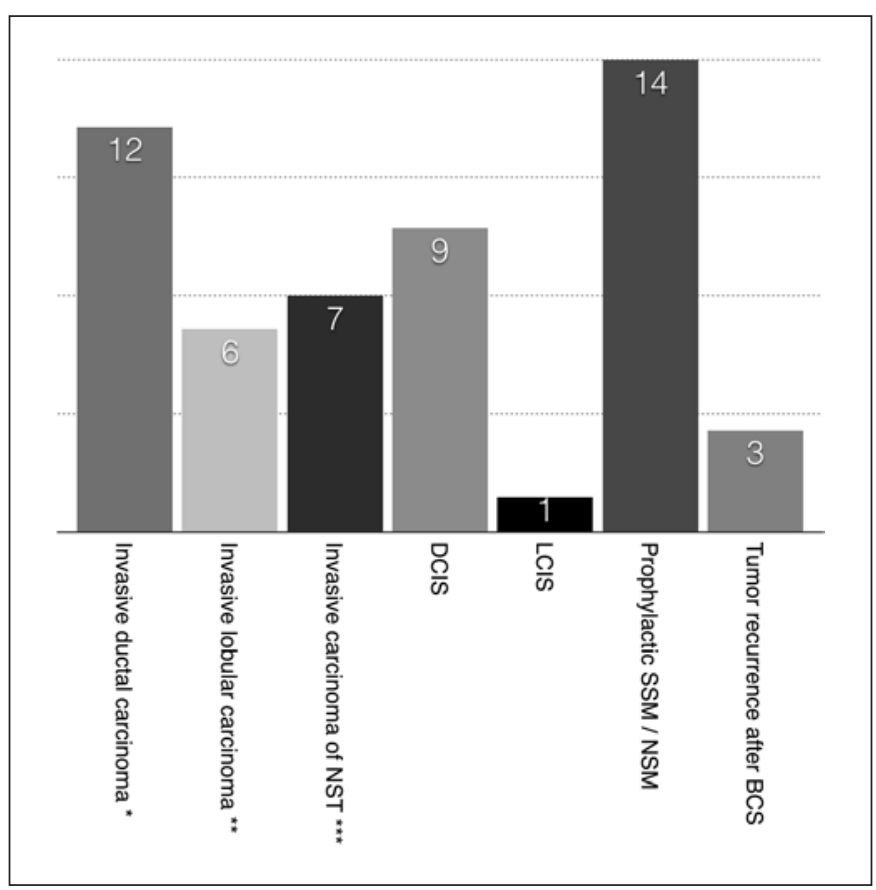

Fig. 2. Distribution of breast carcinoma types in our patient cohort $(n=39)$. Tumor types: invasive ductal carcinoma, invasive lobular carcinoma, invasive carcinoma of no special type (NST), ductal carcinoma in situ (DCIS), lobular carcinoma in situ (LCIS), prophylactic SSM/NSM, tumor recurrence after breast-conserving surgery (BCS). Also included into patient cohort: $4 \times$ Paget's disease (all treated with SSM). ${ }^{*}+8 \times$ DCIS; ${ }^{* *}+1 \times$ DCIS; ${ }^{* * *}+6 \times$ DCIS.

failure), diabetes, lung disease, renal and chemotherapy, menopausal status, and amount of resected breast tissue (g) might have an effect on occurrence of short and/or longterm complications. Additionally, further focus was on tumor entities and recurrence.

\section{Statistical Analysis}

Continuous variables were expressed as median (range) and categorical variables as percentages (frequencies) if not otherwise specified. Cumulative event rates stratified by risk factors were estimated using product limit (Kaplan-Meier) methods and were tested for significant differences between strata using the log-rank test. All continuous risk factors were stratified using age $\geq 50$ years to define increased age, BMI of $\geq 25$ to define overweight, and weight of resected breast tissue $\geq 75$ th percentile ( $438 \mathrm{~g}$ ) to define large breasts. KaplanMeier survival curves were fitted for short-term complications, with illustration restricted to 712 days ( $=2$ years). Patients were censored after the first event. All statistical tests were performed using SAS software (version 9.4, SAS Institute Inc., Cary, NC, USA). A twosided $p$ value of $<0.05$ was considered statistically significant.

\section{Results}

Overall, 50 mastectomies (27 SSM and 23 NSM) with 6 immediate and 35 immediate 2 -stage tissue expander BR (14 free tissue transfers and 36 implant-based BR) amounting to a total of 41 surgical interventions $(n=$ 41) were carried out. SSM and NSM were performed on 39 breast cancer patients (solely by the Plastic Surgery Department within our hospital). Twenty-eight cases involved sentinel lymph node biopsy, among which 5 gave indication for subsequent complete axillary dissection. Treatment algorithms are demonstrated in Figure 1.

Oncological context of our cohort ranged from TNM stage 0 to IIIA (UICC ICD-10 TNM classification) including 25 cases of invasive breast carcinomas, 9 cases of ductal carcinoma in situ, 1 case of lobular carcinoma in situ, and 3 cases of recurrence after breast-conserving therapy. The distribution of carcinoma types is visualized in Figure 2. Further details about our patient pool are shown in Table 1.

After performing initial SSM/NSM, in $26 \%$ of all treated patients, histopathological examination revealed remaining tumor cells in the border regions (R1 resection). Therefore, revision surgery in order to achieve R0 resection status was carried out (for oncologic reasons, implants or expanders were changed during this procedure). Tumor recurrences in our patient cohort were detected in 4 patients (11.8\%) after performing oncologic SSM/NSM, including 2 patients with local recurrence $(5.9 \%)$ and 2 patients with distant recurrence (5.9\%). During the given follow-up interval, 1 patient, who suffered from distant recurrence, passed away. 
A
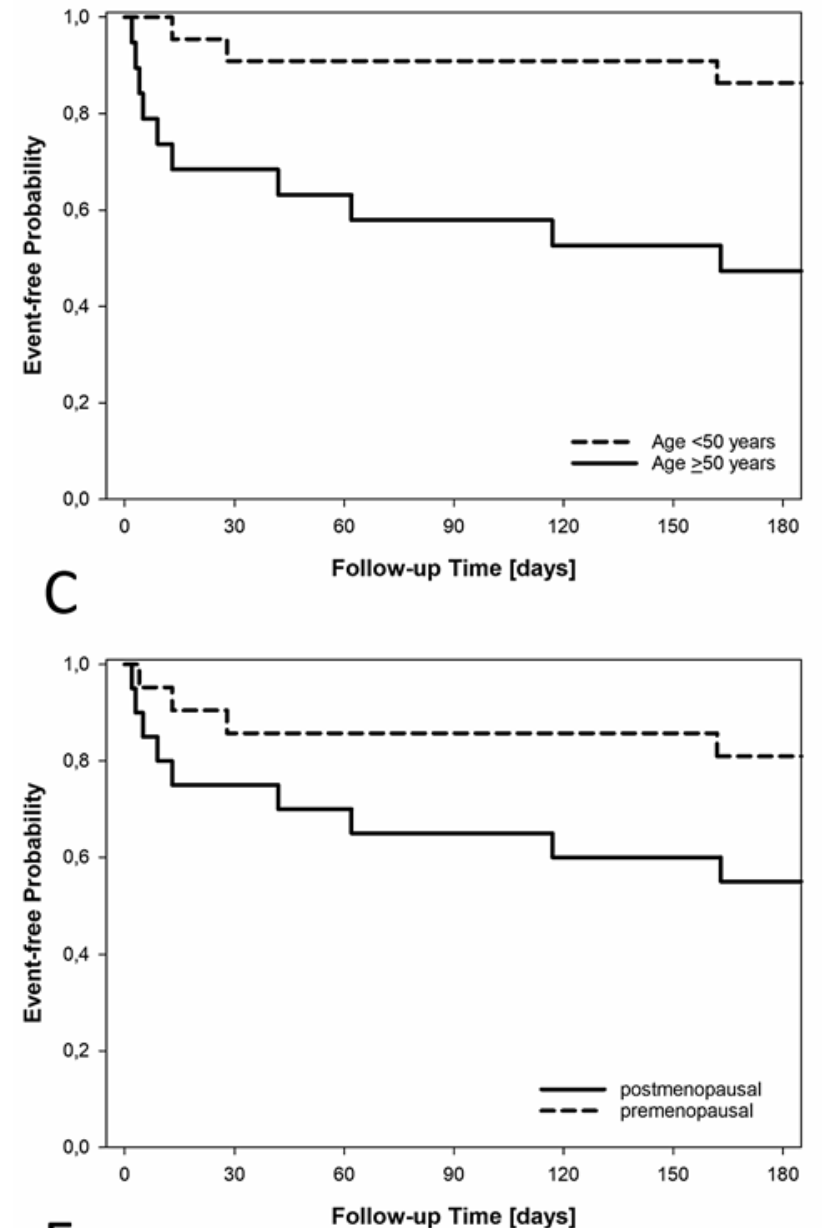

$\mathrm{E}$

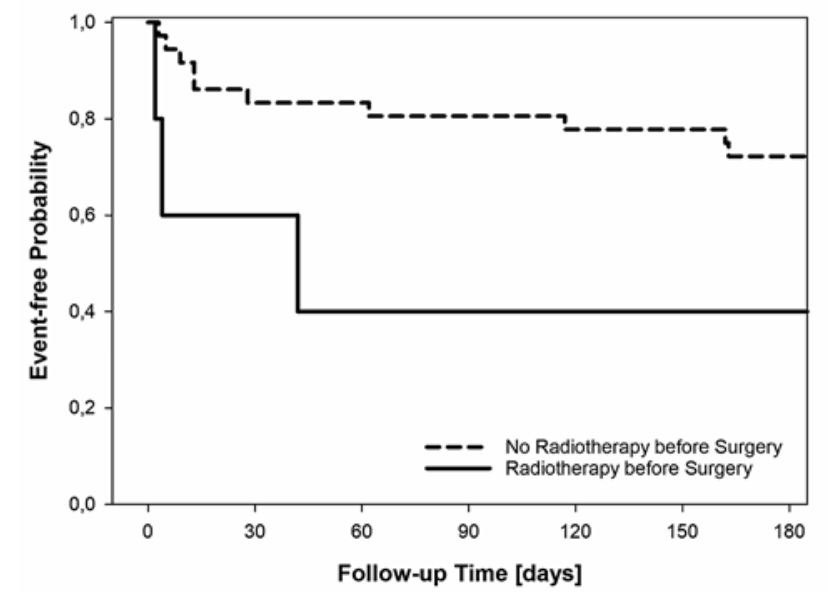

B
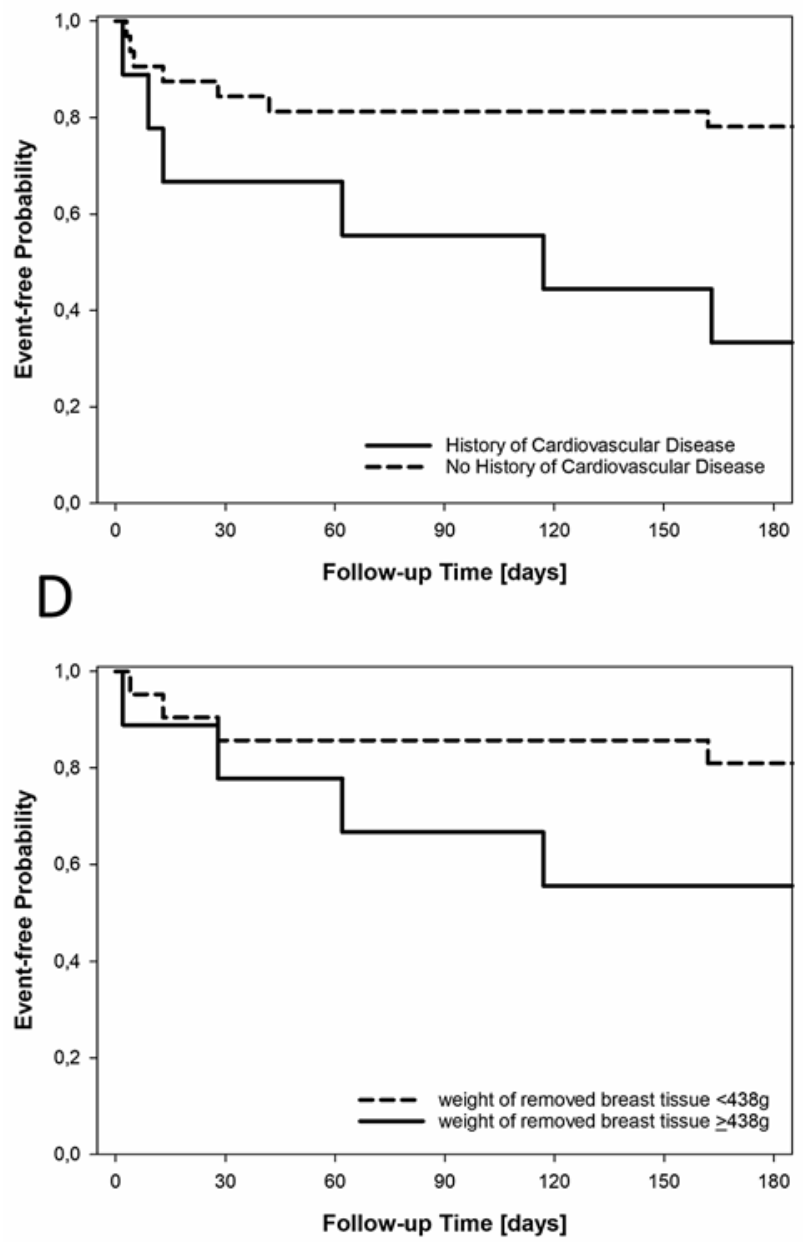

\section{Kaplan-Meier estimates of the probability of short-term complications}

Fig. 3. Kaplan-Meier estimates of the probability of short-term complications stratified by age ( $<50$ and $\geq 50$ years; patients with an increased age were more likely to develop short-term complications; $p=0.006 ; \mathbf{A}$ ), by history of cardiovascular disease (patients with a history of cardiovascular disease showed the tendency to develop short-term complications; $p=0.01$; B), by menopausal status (postmenopausal status was associated with an increased short-term complication rate at a $p$ value of $0.07 ; \mathbf{C})$, by weight of removed breast tissue ( $<438$ vs. $\geq 438$ g; increased weight of removed breast tissue [ $\geq 438 \mathrm{~g}$, 75th percentile] was connected with an increased short-term complication rate at a $p$ value of $0.09 ; \mathbf{D}$ ), and by history of radiotherapy (having a history of radiotherapy before breast surgery [SSM/NSM] was associated with an increased short-term complication rate at a $p$ value of 0.06 ; E). 
Table 2. Overall complication rate

\begin{tabular}{|c|c|c|c|c|c|c|c|c|}
\hline & Skin necrosis & Infection & Seroma & Hematoma & Implant exposure & Implant malposition & Implant loss & Total \\
\hline Short-term complications, $n$ (\%) & $5(10)$ & $1(2)$ & $2(4)$ & $1(2)$ & $1(2)$ & - & - & $10(20)$ \\
\hline Long-term complications, $n(\%)$ & - & - & - & - & - & $4(8)$ & $1(2)$ & $5(10)$ \\
\hline Overall complication rate, $n(\%)$ & & & & & & & & $15(30)$ \\
\hline
\end{tabular}

Listing of short-term complications such as skin necrosis, infection, seroma, hematoma, and implant exposure as well as long-term complications such as implant malposition and implant loss in our patient cohort $(n=39)$. Overall complication rate is $30 \%$ ( 15 complication events/50 SSM/NSM).

Table 3. Publications focusing on risk factors for immediate implant-based breast reconstruction after SSM compared to our patient cohort

\begin{tabular}{|c|c|c|c|}
\hline Characteristics & Proven to be risk factor & Not proven to be risk factor & Our study results \\
\hline Age & $\begin{array}{l}n=157 \text { (Bailey et al. [14], 1989) } \\
n=309 \text { (Woerdeman et al. [9], 2007/age }>43 \text { years) } \\
n=120 \text { (Woerdeman et al. [17], 2006/age }>44 \text { years) } \\
n=876 \text { (Hirsch et al. [8], 2014/age }>50 \text { years; } \\
\text { NSM/SSM and radical mastectomy patients included) }\end{array}$ & $\begin{array}{l}n=112(\text { Furey et al. }[25], 1994) \\
n=130(\text { Nahabedian et al. }[26], 2003) \\
n=102(\text { Kobraei et al. }[18], 2012)\end{array}$ & $\begin{array}{l}n=39 \\
\text { age }>50(p<0.05), \text { also } \\
\text { postmenopausal } \\
\text { patients }(p<0.1)\end{array}$ \\
\hline Smoking & $\begin{array}{l}n=157 \text { (Bailey et al. [14], 1989) } \\
n=37 \text { (Zimmermann et al. [13], 2015) }\end{array}$ & $\begin{array}{l}n=130(\text { Nahabedian et al. [26], 2003) } \\
n=102 \text { (Kobraei et al. [18], 2012) } \\
n=309 \text { (Woerdeman et al. [9], 2007/but } \\
\text { risk factor for implant loss!) }\end{array}$ & - \\
\hline BMI & $\begin{array}{l}n=90(\text { Vinton et al. }[15], 1990) \\
n=37(\text { Hultman and Daiza [5], 2003) } \\
n=158(\text { Munhoz et al. [16], 2013) } \\
n=37(\text { Zimmermann et al. }[13], 2015)\end{array}$ & $\begin{array}{l}n=102(\text { Kobraei et al. [18], 2012/BMI >27) } \\
n=309 \text { (Woerdeman et al. [9], 2007/but } \\
\text { risk factor for implant loss!) }\end{array}$ & - \\
\hline $\begin{array}{l}\text { History of } \\
\text { radiotherapy }\end{array}$ & $\begin{array}{l}n=37 \text { (Hultman and Daiza [5], 2003) } \\
n=102 \text { (Kobraei et al. [18], 2012/only higher risk for } \\
\text { implant loss, not for complications) }\end{array}$ & - & $\begin{array}{l}n=39 \\
(p<0.06)\end{array}$ \\
\hline $\begin{array}{l}\text { Amount of } \\
\text { resected breast } \\
\text { tissue }\end{array}$ & $\begin{array}{l}n=309 \text { (Woerdeman et al. [9], 2007/weight of } \\
\text { specimen }>548 \mathrm{~g} \text { ) }\end{array}$ & - & $\begin{array}{l}n=39 \\
\text { weight of specimen } \\
>438 \mathrm{~g}(p<0.1)\end{array}$ \\
\hline
\end{tabular}

Literature overview about publications focusing on risk factors for implant-based reconstruction immediately after SSM [5, 8, 9, 13-18, 25, 26]. As opposed to this, in our study, 39 patients with a total of 6 immediate and 35 immediate 2-stage tissue expander breast reconstructions (BR) were included. Risk factors such as age, smoking, BMI, general health factors, history of radiotherapy, and amount of resected breast tissue are compared. $n=$ number of patients analyzed in each study.

\section{Follow-Up}

Median follow-up was 2 years and 5 months (range 4 months to 5 years and 1 month). Within this interval, a total of 15 complications occurred, mostly within the first 6 months after SSM/NSM (10 events). Ten postoperative short-term (in $20 \%$ of all patients) and 5 long-term complications (in $10 \%$ of all patients) were detected in our patient cohort. All details about short- and long-term complications are listed in Table 2.

\section{Associations with Short-Term Complications}

In univariate analysis, statistically significant risk factors for short-term complications included increased age (event-free probability at 6 months of 0.47 vs. 0.86 for patients $\geq 50$ years and $<50$ years; $p=0.006$; Fig. $3 \mathrm{~A}$ ) and prior history of cardiovascular disease (event-free probability at 6 months of 0.33 vs. 0.78 for patients with and without prior history of cardiovascular disease, respectively; $p=0.01$; Fig. $3 \mathrm{~B}$ ). Increased but not significant risk factors included postmenopausal status (event-free probability at 6 months of 0.55 vs. 0.81 for post- and pre- 
menopausal patients, respectively; $p=0.07$; Fig. $3 \mathrm{C}$ ), weight of resected breast tissue $>75$ th percentile (eventfree probability at 6 months of 0.56 vs. 0.83 for patients with $\geq 438$ vs. $<438$ g resected breast tissue; $p=0.09$; Fig. 3D), and radiotherapy prior to SSM/NSM (eventfree probability at 6 months of 0.40 vs. 0.72 for patients with and without radiotherapy prior to SSM/NSM, respectively; $p=0.06$; Fig. $3 \mathrm{E}$ ). No statistically significant association was observed for smoking, obesity, alcohol abuse, drug abuse, other general health factors (except cardiovascular disease), hyper-/hypothyroidism, or history of chemotherapy.

\section{Discussion}

As a treating physician, it is always imperative to decide if a certain surgical technique is explicitly suitable for the given (individual) patient. Therefore, it is fundamental to localize in advance certain risk factors that might have a negative impact on patient recovery after SSM/ NSM. In our study, age $>50$ years $(p<0.05)$ and personal history of cardiovascular disease $(p<0.05)$ were associated with an increased statistically significant complication rate. Nevertheless, if safely employed, SSM and NSM are valuable treatment options for patients suffering from breast cancer. In the following, the risk factors are discussed in accordance with the current scientific literature.

\section{Age}

One possible explanation for older age being a risk factor for performing SSM/NSM could be explained by elderly patients having comparatively thinner skin than younger ones [7]. In addition to that, elderly patients typically have more medical comorbidities such as cardiovascular disease or other general health factors compared to younger patients. This could negatively affect their overall complication rate as well [8].

\section{Cardiovascular Disease}

Reviewing the current scientific literature, cardiovascular disease on its own has not been pointed out to be a risk factor for an increased complication rate in SSM/ NSM patients so far. Only Woerdeman et al. [9] showed that cardiovascular disease was the main cause for surgery-related complications in the general health factor group, which has been proven to be a statistically significant overall risk factor. The authors stated that cardiovascular disease led to ongoing vessel damage and therefore a greater risk of, for example, skin necrosis is given after the execution of NSM/SSM [9]. This theory is also supported by the authors of this paper.

In our retrospective study, other risk factors including history of radiotherapy, postmenopausal status, and vol- ume of resected breast tissue were also associated with an increased complication rate, but these were not found to be statistically significant.

Previous radiotherapy in the breast region is said to increase the complication rate after BR [10,11]. For example, a higher risk of a skin breakdown due to decreased vitality of the radiated tissue is given [10]. Interestingly, neoadjuvant chemotherapy was not detected to be a significant risk factor for higher complication rates after SSM/NSM in our patient cohort. In the current scientific literature, radiotherapy is said to have a stronger impact on increased complication rates than, for example, chemotherapy [12].

Postmenopausal status is also connected to older patient age, which has been shown various times to be a risk factor for such surgery [8]. As far as hormone status change might play a role, this should be an interest for further scientific investigations.

Large volume of resected breast tissue has been identified as a risk factor by some authors [9]. A reason for this might be the decreased perfusion of the relatively wide skin flaps, which result from SSM in patients with larger breasts [9]. Also, in larger breasts, increased risk of seroma formation with concomitant higher infection rate could be another explanation for increased complication rate [12].

On the other hand, in our retrospective study, neither, for example, obesity, alcohol abuse nor smoking were shown to be risk factors for postoperative complications, whereas some publications can be found in the current literature confirming a connection between these factors and increased complication rates $[5,13-16]$.

Our patient cohort demonstrated an overall complication rate of $30 \%$, including a $10 \%$ skin necrosis and a $2 \%$ implant loss rate. Complication rates reported in the scientific literature range from 11.1 to $30 \%$ [17-19]. In our study, the amount of different complications, which was looked for, was more extensive compared to other publications [17-19]. Additionally, many publications only strictly focus on mastectomies in the setting of immediate $B R$. But the nature of our patient population required that we had to include many cases of immediate 2 -stage tissue expander BR, in which SSM/NSM was followed by direct application of a temporary expander after being finally replaced by a permanent implant or free tissue transfer in a follow-on operation. Our complication rates are therefore consequently not directly comparable to those derived from studies that consider SSM/NSM in the setting of immediate reconstruction alone. A complete overview of our complication rates as compared to already published postoperative outcomes of SSM/NSM in the setting of only immediate implant-based reconstruction are demonstrated in Table 3 . Here, a broad heterogeneity concerning certain risk factors can be seen. The authors 
therefore believe that further research is needed within this medical field.

Also, in our patient cohort, tumor recurrence rates were comparable to previously published recurrence rates referring to conventional mastectomy and SSM/ NSM $[6,16,17,20-24]$. This data can be used as quality control for performed oncologic surgeries.

\section{Conclusion}

If used in the context of thoughtful preoperative patient selection protocols, SSM and NSM offer a promising therapeutic option for achieving optimal aesthetic and oncologic outcomes. In our study, statistically increased complication rates were associated with age $>50$ years and having a personal history of cardiovascular disease. Increased but not significant risk factors included postmenopausal status, radiotherapy prior to SSM/NSM, and weight of resected breast tissue $>438 \mathrm{~g}$. Furthermore, in our patient cohort, tumor recurrence rates were comparable to previously published recurrence rates referring to conventional mastectomy and SSM/NSM.

\section{Acknowledgement}

We are grateful to Mr. Nicco Krezdorn and Mrs. Marvee Turk for English text editing.

\section{Statement of Ethics}

This research project was designed in accordance with the national law and the World Medical Association Declaration of Helsinki (1964) with its ethical principles for medical research involving human subjects and subsequent amendments. Furthermore, the subjects have given their informed consent.

\section{Disclosure Statement}

The authors declare no conflicts of interest.

\section{Funding Sources}

No financial contribution of any kind has supported this publication. No grants were accepted for this publication. None of the authors has any personal or institutional financial interest in the drugs, materials, or devices described in this paper.

\section{References}

1 Agha RA, Wellstead G, Sagoo H, Al Omran Y, Barai I, Rajmohan S, et al. Nipple sparing versus skin sparing mastectomy: a systematic review protocol. BMJ Open. 2016 May; 6(5):e010151.

2 Toth BA, Lappert P. Modified skin incisions for mastectomy: the need for plastic surgical input in preoperative planning. Plast Reconstr Surg. 1991 Jun;87(6):1048-53.

3 Hinton CP, Doyle PJ, Blamey RW, Davies CJ, Holliday HW, Elston CW. Subcutaneous mastectomy for primary operable breast cancer. Br J Surg. 1984 Jun;71(6):469-72.

4 Murthy V, Chamberlain RS. Nipple-sparing mastectomy in modern breast practice. Clin Anat. 2013 Jan;26(1):56-65.

5 Hultman CS, Daiza S. Skin-sparing mastectomy flap complications after breast reconstruction: review of incidence, management, and outcome. Ann Plast Surg. 2003 Mar; 50(3):249-55.

6 Romics L Jr, Chew BK, Weiler-Mithoff E, Doughty JC, Brown IM, Stallard S, et al. Tenyear follow-up of skin-sparing mastectomy followed by immediate breast reconstruction. Br J Surg. 2012 Jun;99(6):799-806.

7 Longo C, Casari A, Beretti F, Cesinaro AM, Pellacani G. Skin aging: in vivo microscopic assessment of epidermal and dermal changes by means of confocal microscopy. J Am Acad Dermatol 2013;68:e73-82e.
8 Hirsch EM, Seth AK, Kim JY, Dumanian GA, Mustoe TA, Galiano RD, et al. Analysis of risk factors for complications in expander/implant breast reconstruction by stage of reconstruction. Plast Reconstr Surg. 2014 Nov; 134(5):692e-9.

9 Woerdeman LA, Hage JJ, Hofland MM, Rutgers EJ. A prospective assessment of surgical risk factors in 400 cases of skin-sparing mastectomy and immediate breast reconstruction with implants to establish selection criteria. Plast Reconstr Surg. 2007 Feb;119(2):455-63.

10 Devulapalli C, Bello RJ, Moin E, Alsobrooks J, Fallas PB, Ohkuma R, et al. The Effect of Radiation on Quality of Life throughout the Breast Reconstruction Process: A Prospective, Longitudinal Pilot Study of 200 Patients with Long-Term Follow-Up. Plast Reconstr Surg. 2018 Mar;141(3):579-89.

11 Mokbel R, Mokbel K. Skin-sparing mastectomy and radiotherapy: an update. Int Semin Surg Oncol. 2006 Oct;3(1):35.

12 Lam TC, Borotkanics R, Hsieh F, Salinas J, Boyages J. Immediate Two-Stage Prosthetic Breast Reconstruction Failure: Radiation Is Not the Only Culprit. Plast Reconstr Surg. 2018 Jun;141(6):1315-24.

13 Zimmermann CRS, Knauer M, Grünert J. Brustrekonstruktion nach hautsparender Mastektomie bei Mammakarzinom - eine Analyse von 50 Fällen. Paper presented at: DGPRAEC; Berlin, 2015.

14 Bailey MH, Smith JW, Casas L, Johnson P, Serra E, de la Fuente R, et al. Immediate breast reconstruction: reducing the risks. Plast Reconstr Surg. 1989 May;83(5):845-51.
15 Vinton AL, Traverso LW, Zehring RD. Immediate breast reconstruction following mastectomy is as safe as mastectomy alone. Arch Surg. 1990 Oct;125(10):1303-7.

16 Munhoz AM, Aldrighi CM, Montag E, Arruda EG, Aldrighi JM, Gemperli R, et al. Clinical outcomes following nipple-areola-sparing mastectomy with immediate implantbased breast reconstruction: a 12-year experience with an analysis of patient and breast-related factors for complications. Breast Cancer Res Treat. 2013 Aug;140(3): 545-55.

17 Woerdeman LA, Hage JJ, Smeulders MJ, Rutgers EJ, van der Horst CM. Skin-sparing mastectomy and immediate breast reconstruction by use of implants: an assessment of risk factors for complications and cancer control in 120 patients. Plast Reconstr Surg. 2006 Aug; 118(2):321-30; discussion 331-2.

18 Kobraei EM, Nimtz J, Wong L, Buseman J, Kemper P, Wright $\mathrm{H}$, et al. Risk factors for adverse outcome following skin-sparing mastectomy and immediate prosthetic reconstruction. Plast Reconstr Surg. 2012 Feb; 129(2):234e-41e.

19 Kim SW, Lee HK, Kang SM, Kang TH, Yoon CS, Ko SS, et al. Short-term outcomes of immediate breast reconstruction using an implant or tissue expander after mastectomy in breast cancer patients. Breast Cancer. 2016 Mar;23(2):279-85. 
20 Simmons RM, Fish SK, Gayle L, La Trenta GS, Swistel A, Christos P, et al. Local and distant recurrence rates in skin-sparing mastectomies compared with non-skin-sparing mastectomies. Ann Surg Oncol. 1999 Oct-Nov; 6(7):676-81.

21 Foster RD, Esserman LJ, Anthony JP, Hwang ES, Do H. Skin-sparing mastectomy and immediate breast reconstruction: a prospective cohort study for the treatment of advanced stages of breast carcinoma. Ann Surg Oncol. 2002 Jun;9(5):462-6.
22 Medina-Franco H, Vasconez LO, Fix RJ, Heslin MJ, Beenken SW, Bland KI, et al. Factors associated with local recurrence after skinsparing mastectomy and immediate breast reconstruction for invasive breast cancer. Ann Surg. 2002 Jun;235(6):814-9.

23 Lanitis S, Tekkis PP, Sgourakis G, Dimopoulos N, Al Mufti R, Hadjiminas DJ. Comparison of skin-sparing mastectomy versus nonskin-sparing mastectomy for breast cancer: a meta-analysis of observational studies. Ann Surg. 2010 Apr;251(4):632-9.
24 Missana MC, Laurent I, Germain M, Lucas S, Barreau L. Long-term oncological results after 400 skin-sparing mastectomies. J Visc Surg. 2013 Nov; 150(5):313-20.

25 Furey PC, Macgillivray DC, Castiglione CL, Allen L. Wound complications in patients receiving adjuvant chemotherapy after mastectomy and immediate breast reconstruction for breast cancer. J Surg Oncol. 1994 Mar; 55(3):194-7.

26 Nahabedian MY, Tsangaris T, Momen B, Manson PN. Infectious complications following breast reconstruction with expanders and implants. Plast Reconstr Surg. 2003 Aug; 112(2):467-76. 